\title{
Chapter 18 CFD Study of DTU 10 MW RWT Aeroelasticity and Rotor-Tower Interactions
}

\author{
Sergio González Horcas, François Debrabandere, Benoît Tartinville, \\ Charles Hirsch, and Grégory Coussement
}

\begin{abstract}
A numerical analysis of the DTU 10 MW RWT wind turbine aerodynamics is presented in this work. The development of an innovative methodology based on three-dimensional computational fluid dynamics allowed to tackle two challenging problems related to this application. On one hand, the impact of blade deflections on rotor performance was assessed in a rotor-only context. Different blade configurations were studied, including the installation of Gurney flaps and the consideration of prebending and preconing. On the other hand, flow unsteadiness of the full machine (i.e. including the tower) was modeled by means of the Non-Linear Harmonic method. This approach allowed to characterize local aspects of the flow and the impact of rotor-tower interactions on the computed loads.
\end{abstract}

\subsection{Introduction}

Industry standards for the aeroelastic simulations of horizontal axis wind turbines are based on the Blade Element Momentum (BEM) theory. For classical machine designs, such a method offers a very good computational efficiency and an acceptable flow response. BEM base formulation has been improved along with onshore wind turbines evolution, thanks to the introduction of additional sub-models (Jonkman and Buhl 2007; Heege et al. 2013). The accuracy of this approach is however limited when dealing with large Offshore Wind Turbine (OWT) rotors due to the existence of highly skewed flows and heavy detachments. Hence, the use of more sophisticated Computational Fluid Dynamics (CFD) techniques is justified.

\footnotetext{
S.G. Horcas $(\bowtie) \bullet$ F. Debrabandere • B. Tartinville • C. Hirsch NUMECA International, $189 \mathrm{Ch}$. de la Hulpe, B-1170 Bruxelles, Belgium e-mail: sergio.horcas@gmail.com; francois.debrabandere@numeca.be; benoit.tartinville@numeca.be; charles.hirsch@numeca.be

G. Coussement

Faculty of Engineering, Fluids-Machines Department, University of Mons, 53 Rue du Joncquois, B-7000 Mons, Belgium

e-mail: gregory.coussement@umons.ac.be
} 
Due to the continuous upscaling of modern OWTs, important aeroelastic effects are also expected. Traditional CFD approaches do not consider the flexibility of the rotor. However, blade deflections can have a non negligible impact on the machine performance, and a possible blade-tower impact should be considered at the design stage. This requires the consideration of rotor structural models in CFD computations. Due to the lack of publicly available industrial configurations, previous studies concerning wind turbines aeroelasticity are based on the so-called academic or reference designs. In this group we find the works of Corson et al. (2012) for the SNL-100-00 blade and the studies of the NREL 5 MW performed by Hsu and Bazilevs (2012) and Yu and Kwon (2014). In all these publications, blade deflections were found to have a direct impact on the final rotor performance.

Previous CFD studies of wind turbine rotors are based on steady flow rotoronly simulations (where only blades, hub and nacelle geometries are considered). Thanks to the problem periodicity when assuming an incoming wind aligned with the rotor axis, a single blade passage is normally meshed. These simulations allow to characterize the local flow behaviour around the wind turbine and its impact on global rotor performance with a reduced computational effort. However, by omitting the tower geometry the main source of flow unsteadiness is also neglected. Indeed, due to the proximity of the rotor to the tower, the generation of complex unsteady flow phenomena is expected. This mechanism is often referred as rotortower interactions. First NREL Phase VI publications assessing this topic revealed the existence of both blade and tower shedding phenomena and fluctuating loads generation related to the blade-tower alignment event (Zahle et al. 2009; Lynch 2011; Wang et al. 2012; Hsu et al. 2014; Li 2014). Similar unsteady effects were computed for the NREL 5 MW studies of Hsu and Bazilevs (2012) and Yu and Kwon (2014), and in the industrial wind turbines publications of Zahle and Sørensen (2008, 2011).

In this chapter high fidelity CFD models were used in order to characterize the rotor aerodynamics of the DTU $10 \mathrm{MW}$ RWT reference wind turbine (Bak et al. 2013), whose main parameters are summarized in Table 18.1. Aeroelasticity and rotor-tower interactions problems were assessed in two independent numerical studies. In Sect. 18.2, rotor-only simulations were performed based on the computational framework for OWT rotors static aeroelasticity analysis developed by Horcas et al. (2014). In particular, the impact of Gurney flaps installation and the effect of prebending and preconing on rotor performance were evaluated. This work can be understood as a continuation of previous DTU $10 \mathrm{MW}$ RWT studies (Horcas et al. 2015a,b). In Sect. 18.3, the flow unsteadiness related to rotor-tower interactions was characterized by means of the Non Linear Harmonics (NLH) method presented by Vilmin et al. (2006).

The present computational analysis was performed using the commercial CFD package FINETM/Turbo (NUMECA International 2013b). This tool was previously validated in the framework of NREL Phase VI rotor-only simulations by other authors (Fan and Kang 2009; Elfarra et al. 2014; Suárez et al. 2015a,b). The

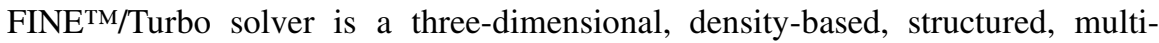


Table 18.1 DTU 10 MW

RWT main parameters

\begin{tabular}{l|l}
\hline Parameter description & Parameter value \\
\hline Cut in wind speed & $4 \mathrm{~m} \mathrm{~s}^{-1}$ \\
\hline Cut out wind speed & $25 \mathrm{~m} \mathrm{~s}^{-1}$ \\
\hline Rated wind speed & $11.4 \mathrm{~m} \mathrm{~s}^{-1}$ \\
\hline Rated power & $10 \mathrm{MW}$ \\
\hline Number of blades & 3 \\
\hline Rotor diameter & $178.3 \mathrm{~m}$ \\
\hline Min. rotor speed & $6 \mathrm{RPM}$ \\
\hline Max. rotor speed & $9.6 \mathrm{RPM}$ \\
\hline Hub height & $119 \mathrm{~m}$ \\
\hline Tower diameter top & $5.5 \mathrm{~m}$ \\
\hline Tower diameter base & $8.3 \mathrm{~m}$ \\
\hline Tower clearance & $18.26 \mathrm{~m}$
\end{tabular}

block finite volume code. A central-difference scheme is employed for the spatial discretization with Jameson type artificial dissipation. A four-stage explicit RungeKutta scheme is applied for the temporal discretization. Multi-grid method, local time-stepping and implicit residual smoothing are used in order to speed-up the convergence.

\subsection{DTU 10 MW RWT Rotor-Only Analysis}

In this section, a complete characterization of DTU 10 MW RWT aeroelasticity in a rotor-only framework is presented. A Reynolds Averaged Navier Stokes (RANS) approach was used in order to perform steady flow simulations of this OWT. Turbulence was considered by means of the Spalart-Allmaras model (Spalart and Allmaras 1992). Rotor was considered either as rigid or flexible. For the latter case, the consideration of a blade structure sub-model was necessary. Mesh deformation was carried out by the 3-steps hybrid method described in Horcas et al. (2015a).

First computations included in Sect. 18.2.1 were based on the standard DTU $10 \mathrm{MW}$ RWT rotor, assuming a rigid configuration. Straight blades were considered, equipped with the so-called Gurney flaps devices at low span range [20\%, $30 \%$ ] (see Fig. 18.1). Obtained results were compared with three-dimensional CFD simulations performed by other authors. The same methodology was used in Sect. 18.2.2 to compare the performance of this standard blade with a clean variant, where the Gurney flaps were removed. Both rigid and flexible rotor configurations were studied. Finally, in Sect. 18.2.3 the impact of of prebending and preconing on DTU 10 MW RWT aeroelastic behaviour is assessed. 
(a)

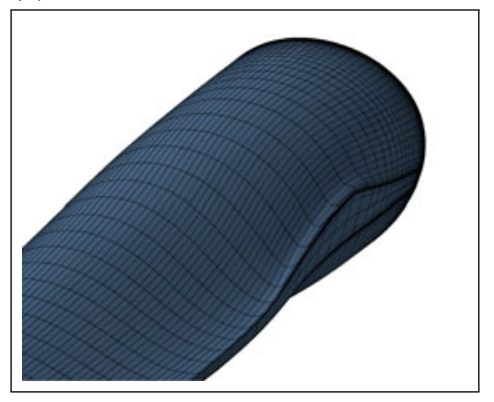

(b)

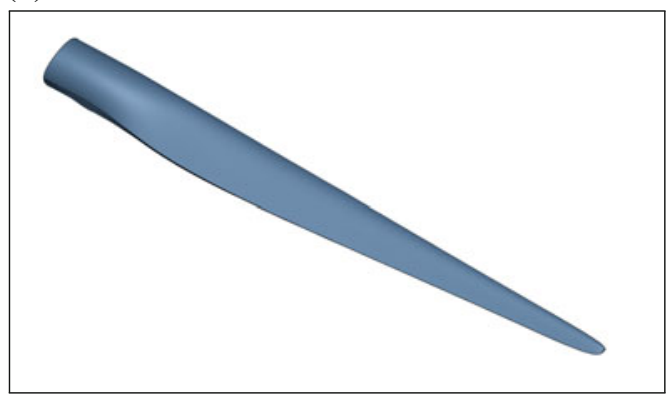

Fig. 18.1 DTU 10 MW RWT straight blade geometry equipped with Gurney flaps. (a) Low span zoom. (b) Global view

Table 18.2 DTU 10 MW

RWT aerodynamic load cases definition

\begin{tabular}{l|c|c}
\hline DLC Identifier & Wind speed $\left[\mathrm{ms}^{-1}\right]$ & RPM \\
\hline FT_WSP07 & 7 & 6.000 \\
\hline FT_WSP08 & 8 & 6.426 \\
\hline FT_WSP09 & 9 & 7.229 \\
\hline FT_WSP10 & 10 & 8.032 \\
\hline FT_WSP11 & 11 & 8.836 \\
\hline
\end{tabular}

${ }^{a}$ FT_WSP11 being very close to the wind turbine design point, it is referred in this document as rated speed

\subsubsection{Steady Aerodynamics, Standard Geometry}

In this section, the DTU $10 \mathrm{MW}$ RWT standard rotor was studied for the $0^{\circ}$ pitch operating range compiled in Table 18.2. The hypothesis of rigid blades was made.

Autogrid5 $5^{\mathrm{TM}}$ structured grids generator was used in order to perform a threedimensional mesh of the DTU 10 MW RWT rotor (NUMECA International 2013a). Blade surfaces as well as original nacelle and hub geometries were included in this process. A blocking topology was established around the blade, putting special attention in the local mesh around the blunt edge and blade tip. A single blade passage was meshed, accounting for $7.2 \times 10^{6}$ nodes and 24 blocks. A first cell size of $3.0 \times 10^{-5} \mathrm{~m}$ was imposed around the considered geometry, in order to properly describe the boundary layer for the studied wind speed range. Flow inlet and outlet were located at 2.2 and 3.2 blade radius from the nacelle respectively. Figure 18.2 shows a global overview of the mesh. For clarity purposes the three blades are displayed, and 1 out of 2 grid lines are skipped. In Fig. 18.3a, the crosssection mesh at mid-span is illustrated. The geometry of Gurney flaps at $20 \%$ of span together with the surrounding cross-section mesh are shown in Fig. 18.3b.

A good agreement in terms of loads prediction with respect to the threedimensional RANS computations described in Bak et al. (2013) and performed with 
(a) (b)

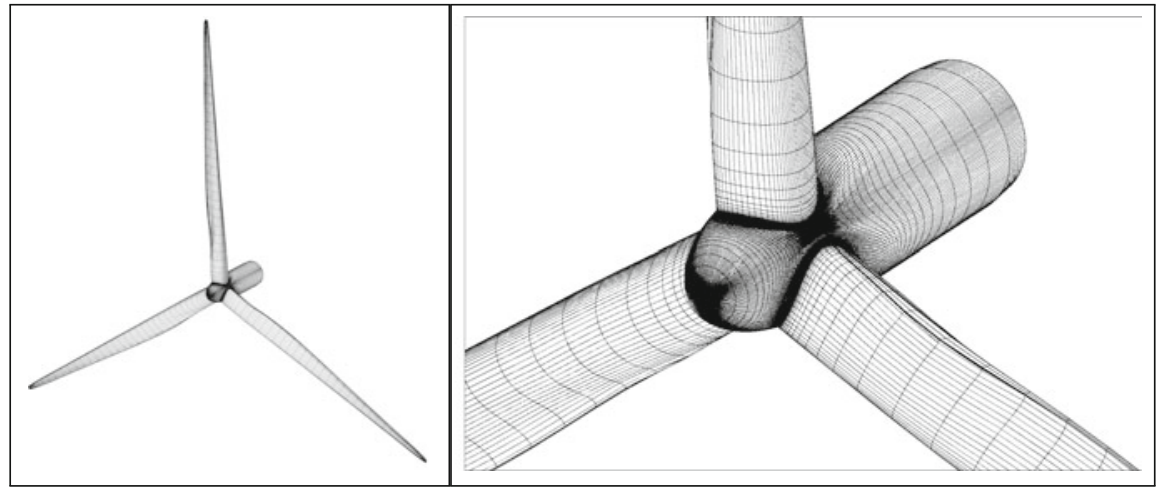

Fig. 18.2 DTU 10 MW RWT surface mesh overview (displayed 1 every 2 grid lines). (a) Global view. (b) Detail of nacelle and low blade span range

(a)

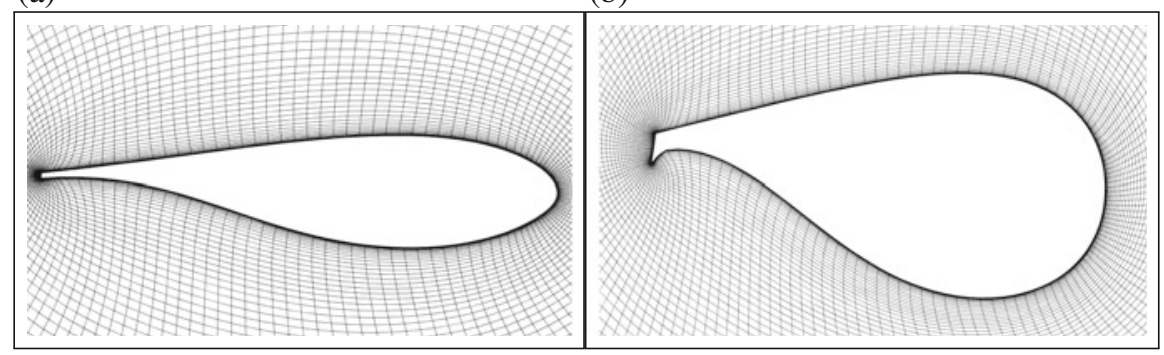

Fig. 18.3 DTU 10 MW RWT cross-section meshes, 20 and $50 \%$ span. (a) $50 \%$ span. (b) $20 \%$ span

EllipSys3D (Sørensen 1995) was observed. A global loads comparison for all the studied operating points is included in Fig. 18.4.

Recirculations were observed near blade trailing edges at low span range. To illustrate this issue, Fig. 18.5 shows the friction streamlines around the DTU $10 \mathrm{MW}$ RWT for the rated speed operating point. This observation is in-line with EllipSys3D computations performed by Zahle et al. (2014), where an important 3D flow behaviour was found up to an approximated radius of $30 \mathrm{~m}$.

\subsubsection{Static Aeroelasticity, Impact of Gurney Flaps}

Original DTU $10 \mathrm{MW}$ RWT blade geometry is equipped with the so-called Gurney flaps at low span range [20\%,30\%]. This device, originally developed for race car applications, consists on a small plate located at the trailing edge. It is used to 


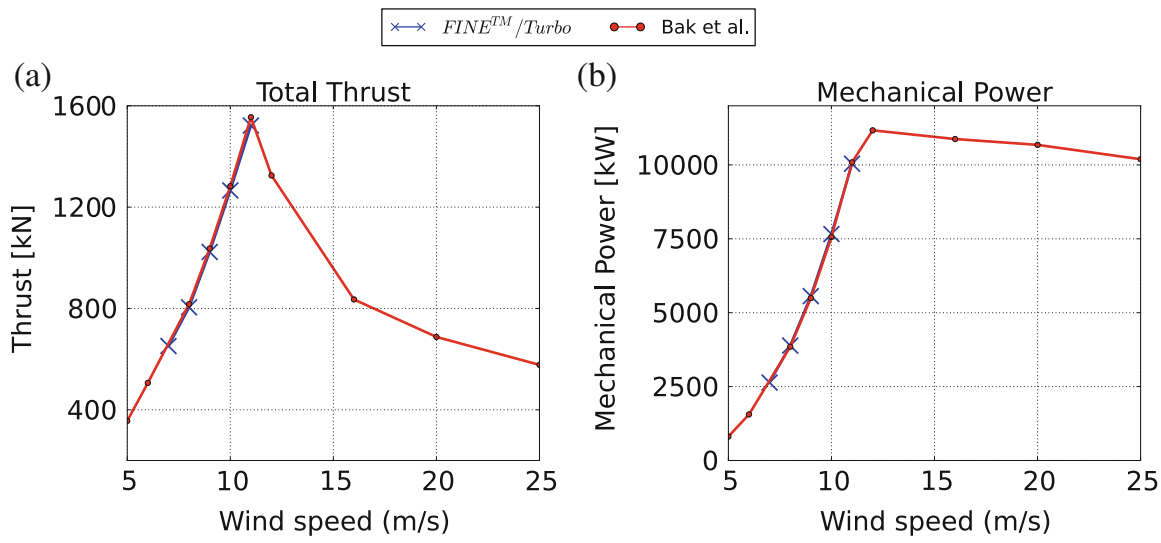

Fig. 18.4 DTU 10 MW RWT total rotor thrust and mechanical power versus wind speed. (a) Total thrust. (b) Mechanical power

(a)

$\mathrm{r}[\mathrm{m}]$

\begin{tabular}{llllllllllllllllll}
0 & 5 & 10 & 15 & 20 & 25 & 30 & 35 & 40 & 45 & 50 & 55 & 60 & 65 & 70 & 75 & 80 & 85 \\
\hline
\end{tabular}

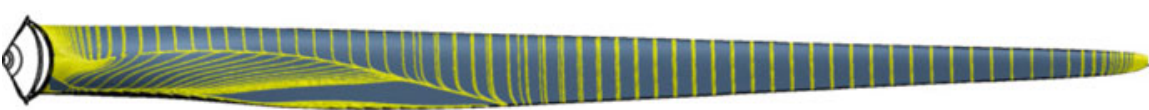

(b)

\begin{tabular}{llllllllllllllllll}
$\mathrm{r}[\mathrm{m}]$ \\
0 & 5 & 10 & 15 & 20 & 25 & 30 & 35 & 40 & 45 & 50 & 55 & 60 & 65 & 70 & 75 & 80 & 85 \\
\hline
\end{tabular}

Fig. 18.5 Friction streamlines at rated speed. (a) Suction surface. (b) Pressure surface

increase the lift produced by the airfoil when operating in separated flow conditions. A low drag penalty is expected. First studies characterizing the performance of this passive device were performed by Liebeck (1978). Figure 18.6 reproduces the conclusions of this work. The beneficial effects of the Gurney flaps installation are explained by the re-attachment of suction side flow close to the trailing edge. In order to evaluate the behaviour of the DTU $10 \mathrm{MW}$ RWT Gurney flaps the load cases of Table 18.2 were studied again in a mesh with clean trailing edges, and compared with previous results. This comparison was performed not only under the hypothesis of rigid blades, but also by considering a flexible rotor.

A new mesh was generated with the same set-up described in Sect.18.2.1, but based on a variant geometry of the DTU 10 MW RWT where the Gurney flaps were replaced by the unmodified blade profiles definition. This new mesh is referred in 
(a)

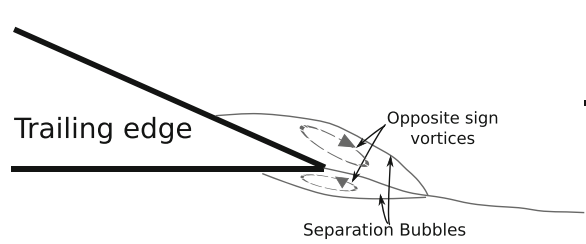

(b)

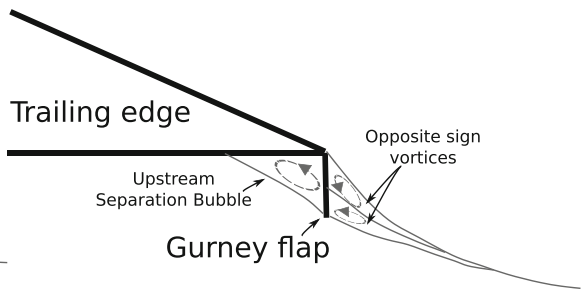

Fig. 18.6 Expected effects on trailing edge flow due to Gurney flaps installation. (a) Clean trailing edge. (b) Trailing edge accounting for a Gurney flap

(a)

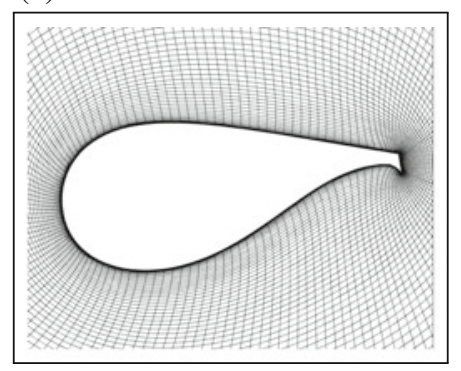

(c)

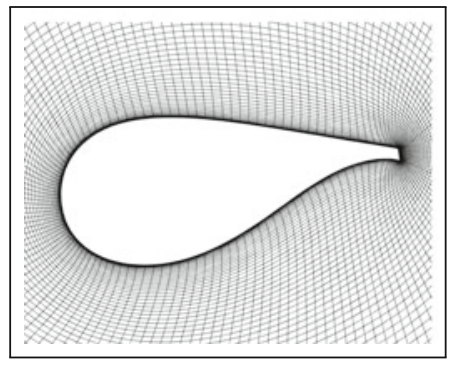

(b)

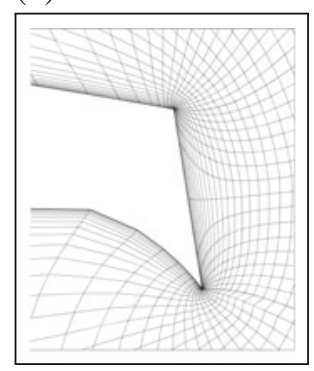

(d)

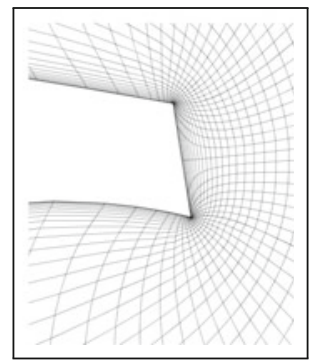

Fig. 18.7 Cross-section meshes at $25 \%$ span for $G$ (Gurney) and $N G$ (no-Gurney) configurations. (a) $G$ cross-section mesh. (b) $G$ trailing edge. (c) $N G$ cross-section mesh. (d) $N G$ trailing edge

this section as no-Gurney, or $N G$. For clarity purposes, the one initially created in Sect. 18.2.1 is referred as Gurney or G. In order to illustrate the differences between $G$ and $N G$ configurations, Fig. 18.7 displays a cross-section of the mesh corresponding to a $25 \%$ of blade span.

For the considered aeroelastic simulations, the blade structure was linearized by means of the Reduced-Order Model (ROM) developed by Debrabandere (2014). A modal analysis was performed within the commercial package Abaqus (Simulia 2008) based on the model provided by Bak et al. (2013). Obtained natural frequencies were compared against the results of the aeroelastic computations of HAWC2 (Larsen and Hansen 2007), a third party software based on blade element 
Table 18.3 DTU 10 MW RWT blade modes, comparison in the absence of rotation

\begin{tabular}{l|l|l|l}
\hline \multicolumn{2}{l|}{ Natural frequency $[\mathrm{Hz}]$} & \multicolumn{2}{l}{ Isolated blade modes } \\
\hline Abaqus & Bak et al. (2013) & Identifier & Description \\
\hline 0.61 & 0.61 & 1 & $1^{\text {st }}$ flap \\
\hline 0.96 & 0.93 & 2 & $1^{\text {st }}$ edge \\
\hline 1.75 & 1.74 & 3 & $2^{\text {nd }}$ flap \\
\hline 2.88 & 2.76 & 4 & $2^{\text {nd }}$ edge \\
\hline 3.58 & 3.57 & 5 & $3^{\text {rd }}$ flap \\
\hline 5.71 & 5.69 & 6 & $1^{\text {st }}$ torsion \\
\hline 5.75 & - & 7 & Mixed flap/torsion \\
\hline 6.16 & 6.11 & 8 & $4^{\text {th }}$ flap \\
\hline- & 6.66 & 9 & $3^{\text {rd }}$ edge \\
\hline
\end{tabular}

Fig. 18.8 Evolution of DTU 10 MW RWT blade frequencies in function of rotational speed (first six modes plotted)

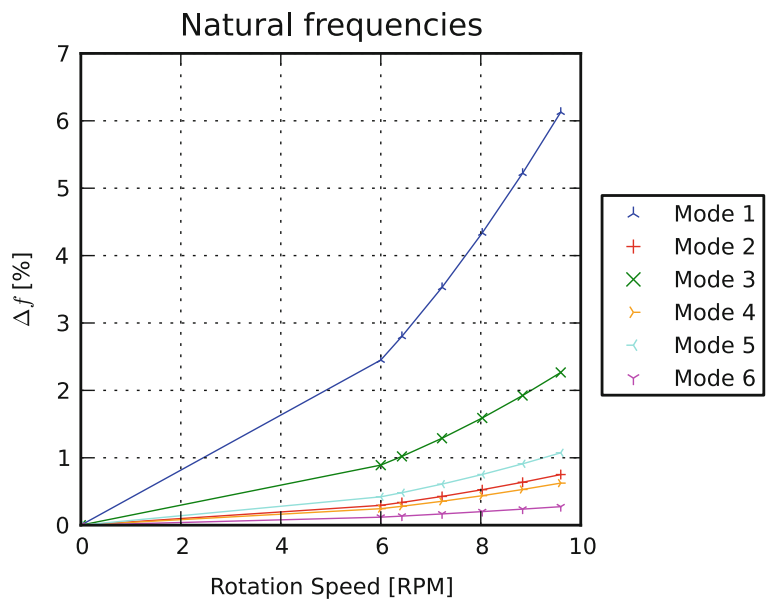

momentum (BEM) theory. Computed frequencies for each identified mode are compiled in Table 18.3. To reduce the computational cost attached to aeroelastic simulations, only the first six frequencies of the obtained modal basis were used to model blade flexibility. A mixed mode was found between first torsion and fourth flap. No pure third edge mode was identified within the considered frequency range. These differences could be explained by the complexity of the astructural models used for natural frequencies extraction.

Additional modal analysis were performed taking into account the centrifugal effects of each one of the analyzed rotor RPMs. This allowed to include the initial blade deformation due to the rotation. In addition, a slight structural frequencies shift was observed. This effect is illustrated in Fig. 18.8, where the variations of blade frequencies against non-rotating frequency are plotted at every RPM. Even if this frequency shifting is not as important as in other rotatory applications including large blade deformations (such as helicopters), a non-negligible value is observed 
(a)

(b)
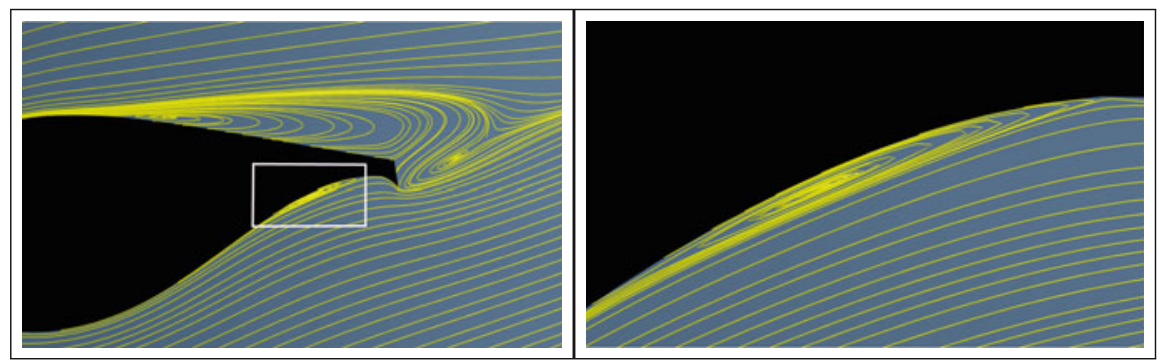

(c)

(d)
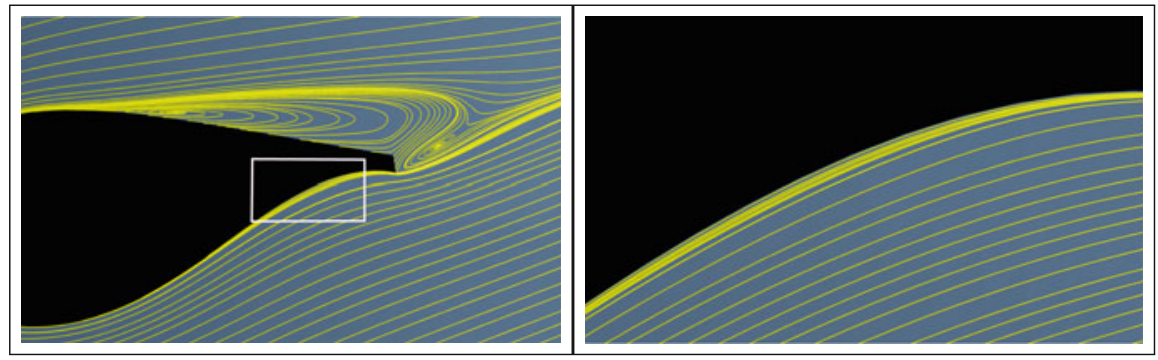

Fig. 18.9 Cross-section streamlines for $r=23 \mathrm{~m}$ at rated speed. Rigid simulations. (a) G (Gurney), global view. (b) $G$ (Gurney), pressure side zoom. (c) $N G$ (no-Gurney), global view. (d) $N G$ (noGurney), pressure side zoom

for the first modes. As an example a difference up to $6.12 \%$ was found for the first mode at 9.6 RPM.

In order to check if the Gurney flaps flow control mechanism illustrated in Fig. 18.6 was reproduced in the DTU 10 MW RWT geometry, a detailed analysis of the rigid configuration at rated speed was performed. Figure 18.9 shows a comparison of the cross-section streamlines at $r=23 \mathrm{~m}$. The generation of the pressure surface separation bubble was visible for the $G$ configuration. A detailed view of this phenomenon is included in Fig. 18.9b. The suppression of the suction surface recirculation, expected after the installation of the Gurney flaps, was not observed. This behaviour was found for the whole low span range, as it can be deduced from the comparison of blade surface streamlines of Fig. 18.10a and b. Indeed, the removal of the Gurney flaps led to a slight decrease of the maximum radius of the suction surface separation (passing from $39.7 \mathrm{~m}$ for $G$ to $38.1 \mathrm{~m}$ for $N G$ ). In addition, the flow around the pressure surface of $N G$ remained attached for the whole blade span, except for a small recirculation bubble located at $r=$ [14.9, 20.3] m (see Fig. 18.10d). A similar flow pattern was observed for all the operating points of Table 18.2.

The benefits of the no-Gurney NG configuration on flow behavior had a direct impact on global rotor performance. Figure 18.11a and b show the global thrust 
(a)

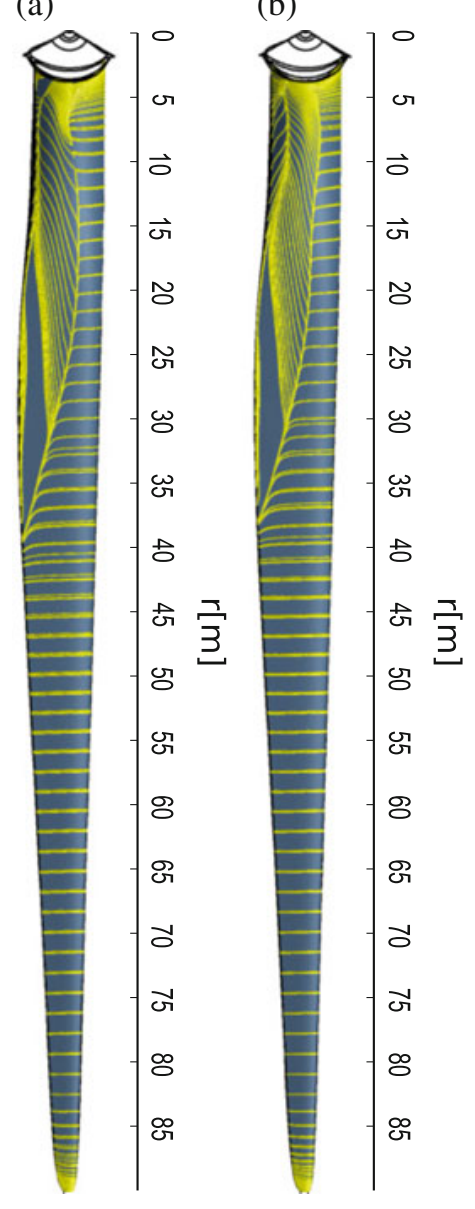

(c)

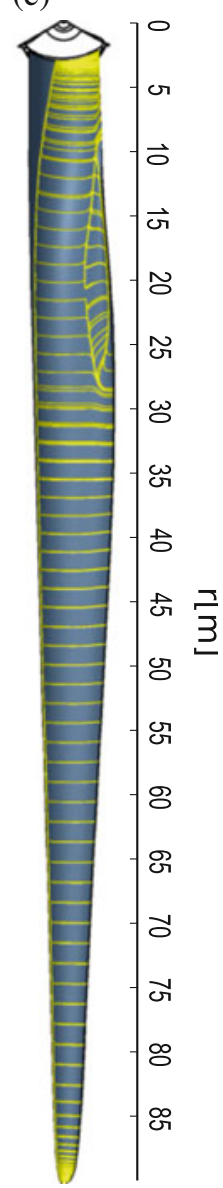

(d)

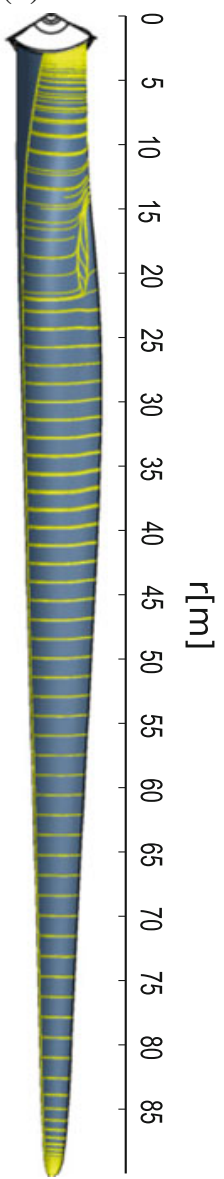

Fig. 18.10 Friction streamlines at rated speed for suction and pressure surfaces (referred as $S S$ and $P S$ respectively). Rigid simulations of $G$ (Gurney) and $N G$ (no-Gurney) configurations. (a) $S S-G$. (b) $S S-N G$. (c) PS-G. (d) $P S-N G$

and mechanical power coefficients, computed for both $G$ and $N G$ configurations. The results for rigid and flexible blade models are included. Global load coefficients were computed based on the following equations:

$$
C_{t, g l o b a l}=\frac{B T}{0.5 \rho U_{\infty}^{2} \pi R^{2}}, C_{p, g l o b a l}=\frac{B \tau \Omega}{0.5 \rho U_{\infty}^{3} \pi R^{2}},
$$

Where $T$ stands for the thrust force generated per blade, $\tau$ is the torque per blade, $B$ stands for the number of blades, $U_{\infty}$ is the incoming fluid speed, $\rho$ is the fluid density, $R$ is the total blade span and $\Omega$ is the rotating speed. 

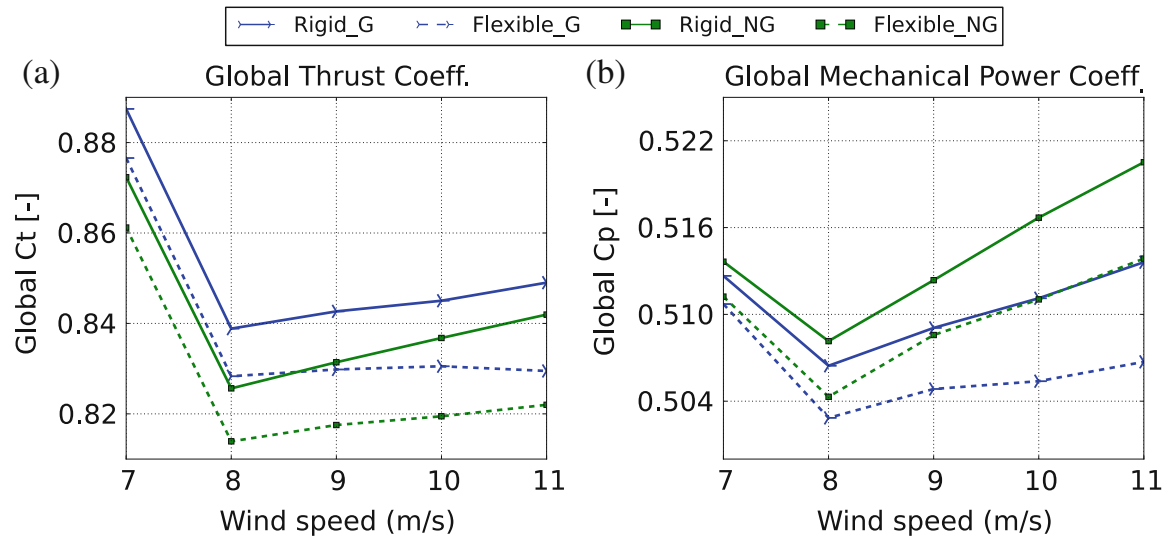

Fig. 18.11 Global load coefficients in function of wind speed for G (Gurney) and NG (no-Gurney) configurations. (a) Global thrust coefficient. (b) Global mechanical power coefficient

\begin{tabular}{|c|c|c|c|c|c|c|c|c|c|}
\hline$\longrightarrow$ & FT_WSP11 G & $\longrightarrow$ & FT_WSP10 G & $\longrightarrow$ & FT_WSP09 G & $\longrightarrow$ & FT_WSP08 G & $\longmapsto$ & FT_WSP07 G \\
\hline$\square$ & FT $W$ & $\square$ & FT WSP10 NG & $\square \square$ & FT_WSP09 NG & $\square \longrightarrow$ & FT_WSP08 NG & $\square$ & FT_WSP07 NG \\
\hline
\end{tabular}

(a) Disp. parallel to rotation axis

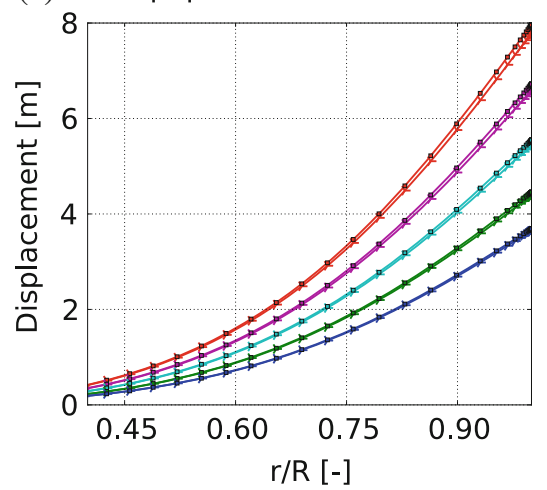

(b) Disp. normal to rotation axis

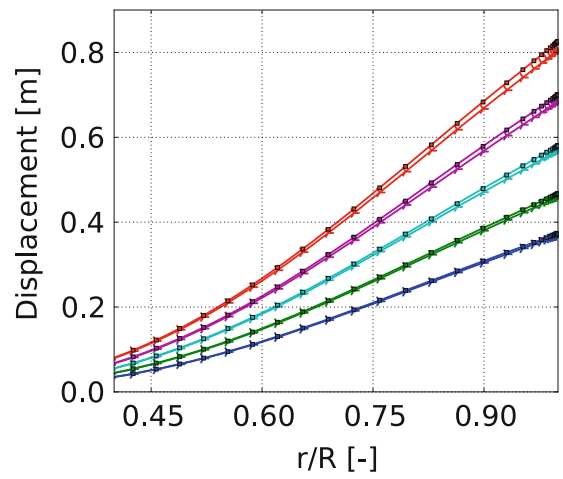

Fig. 18.12 DTU 10 MW RWT blade deformation in function of normalized radius. G (Gurney) and $N G$ (no-Gurney) configurations. (a) Blade axis displacement parallel to rotor axis. (b) Blade axis displacement normal to rotor axis

At rated speed and for the rigid blade model, the installation of Gurney flaps decreased the mechanical power of $1.4 \%$, while the thrust was increased of $0.8 \%$. A similar trend was observed for lower wind speeds. Same remarks concerning the efficiency of Gurney flaps could be made when considering blade elasticity.

A global thrust and mechanical power decrease was observed for both $G$ and $N G$ configurations when considering aeroelasticity. This is related to the important blade deflections experienced by the blade. Figure 18.12 displays the 
computed displacements parallel and normal to the rotor axis (often referred as out-of-rotor plane and in-rotor plane respectively). No significant differences were observed between the deflections corresponding to $G$ and $N G$ geometries. For both configurations, deformation parallel to rotor axis reached the $44 \%$ of the blade tip/tower distance $(18.26 \mathrm{~m})$ at the rated speed operating point.

Based on the presented results, a decrease of the performance of the DTU $10 \mathrm{MW}$ RWT rotor is expected after the integration of the Gurney flaps. Other alternatives in order to avoid the observed flow separation can be found in the literature. In Gaunaa et al. (2013), the use of leading edge slats at low span regions $r / R=[0.8,0.32]$ was studied. Troldborg et al. (2015) considered the installation of vortex generators in order to control flow separation.

\subsubsection{Static Aeroelasticity, Impact of Prebending and Preconing}

The distance between the blade tip and the tower is often referred in the wind energy context as the tower clearance. In order to increase this gap (especially when dealing with large rotors), wind turbine designers use to introduce three geometrical considerations on the assembly:

- Tilt angle: Angle between rotor axis and tower

- Precone angle: Angle between blade axis and rotor axis

- Prebending: Blade deflection towards the incoming wind direction imposed during the blade design stage

The DTU $10 \mathrm{MW}$ RWT accounts for all of them, as shown in Fig. 18.13a, where a sketch from the definition document of Bak et al. (2013) is reproduced. The geometrical effects of prebending, tilt and preconing are highlighted. In an operating wind turbine, the combination of all these modifications will try to align the deformed blade with the tower, as shown in Fig. 18.13b.

The aim of this section is to analyze how these geometrical considerations will impact rotor performance. The results of the already studied straight configuration were compared against a new and more realistic variant, accounting for tower clearance increase devices. Based on the conclusions of Sect. 18.2.2, new simulations were based on a blade geometry without Gurney flaps. In order to explore the whole $0^{\circ}$ operating range of the machine, the load cases from Table 18.2 were analyzed again and compared with the straight-NG configuration results. Both rigid and flexible blades were analyzed.

A new mesh was generated with the same characteristics as the one described in Sect. 18.2.1. Since the introduction of the tilt angle was not compatible with the angular periodicity hypothesis, only the prebending and the preconing were considered. Based on the design specifications from Bak et al. (2013), the new 


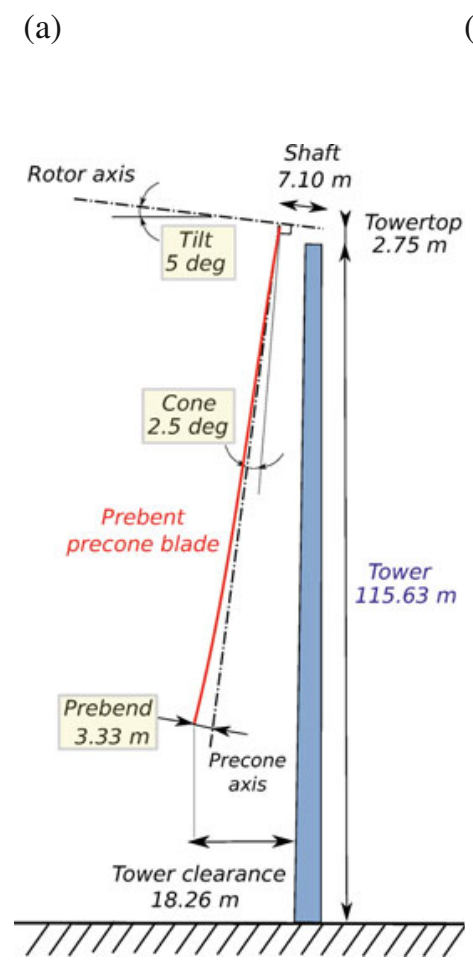

(b)

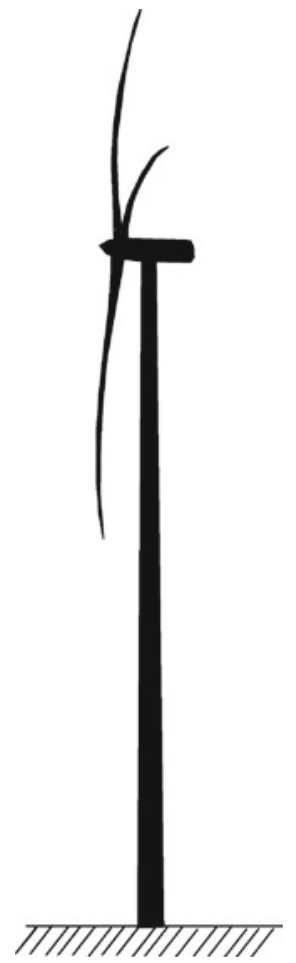

Fig. 18.13 Examples of whole wind turbine assemblies. (a) Sketch of the DTU 10 MW RWT assembly. (b) Representative sketch of a working wind turbine

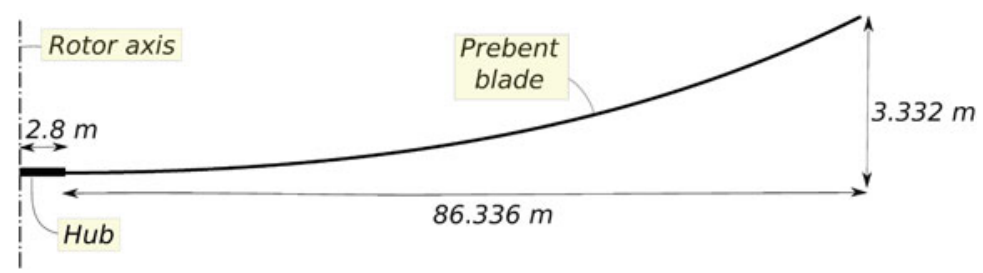

Fig. 18.14 DTU 10 MW RWT axis prebending definition, (reproduced from Bak et al. 2013)

considered geometry was generated by the application of the following geometrical operators on the standard DTU $10 \mathrm{MW}$ RWT configuration:

1. Application of the prebending law definition on the straight blade (see Fig. 18.14)

2. Application of the $2.5^{\circ}$ precone angle to the already prebent blade

Due to the significant geometrical modifications performed on the new prebentprecone blade, a new set of natural structural frequencies and mode shapes was required. The methodology described in Sect. 18.2.2 was used in order to perform 


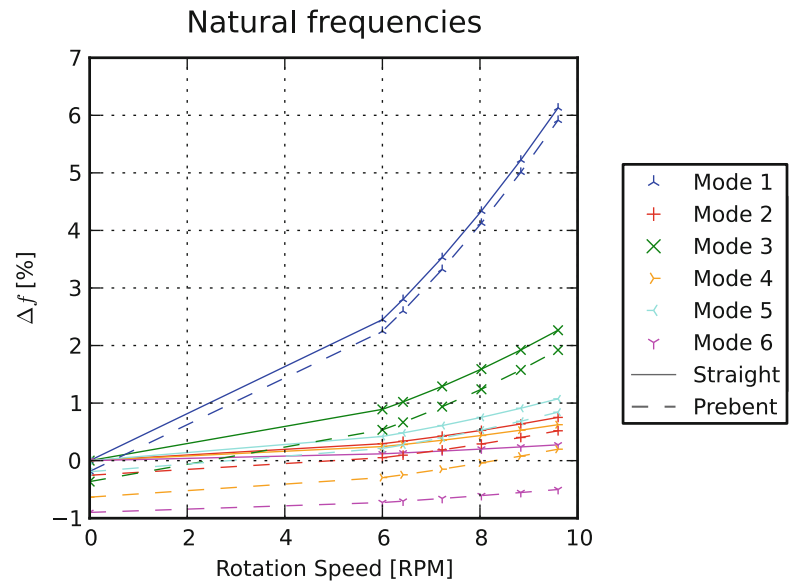

Fig. 18.15 Evolution of DTU 10 MW RWT blade frequencies in function of rotational speed, straight and prebent-precone blades (first six modes plotted)

(a)

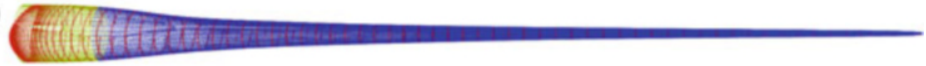

(b)

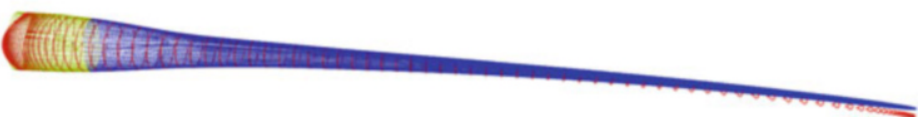

Fig. 18.16 DTU 10 MW RWT modal analysis initial deformation (blue-yellow), superposed to the blade geometry reference (red) at rated speed. (a) Straight blade. (b) Prebent-precone blade

modal analysis for each one of the considered RPM. The same blade modes identified for the straight blade were observed for the new geometry. As previously shown in Fig. 18.8 for the straight configuration, a small RPM dependency was observed. In Fig. 18.15, the relative variations of natural frequencies corresponding to both configurations are compared. They are normalized by the frequency of the non-rotating straight blade. The evolutions of the frequencies with the rotation speed were very similar. Only a constant shift between straight and prebentprecone configuration was observed. This shift tended to increase with the mode number.

A more significant difference was related to the centrifugal effects included in the performed modal analysis. Indeed, an important initial deformation was observed for the prebent-precone configuration, due to offset of the blade geometry. In Fig. 18.16, the initial deformation (in blue-yellow) is superposed to the corresponding blade geometries (in red) for the rated speed operating point. While no difference was visible for the straight configuration (Fig. 18.16a), the centrifugal effects tended to straighten up the blade (Fig. 18.16b). As performed in the previous 


$\square \longrightarrow$ FT_WSP11 $\longrightarrow$ FT_WSP10 $\square-$ FT_WSP09 $\longrightarrow$ FT_WSP08 $\square$ FT_WSP07
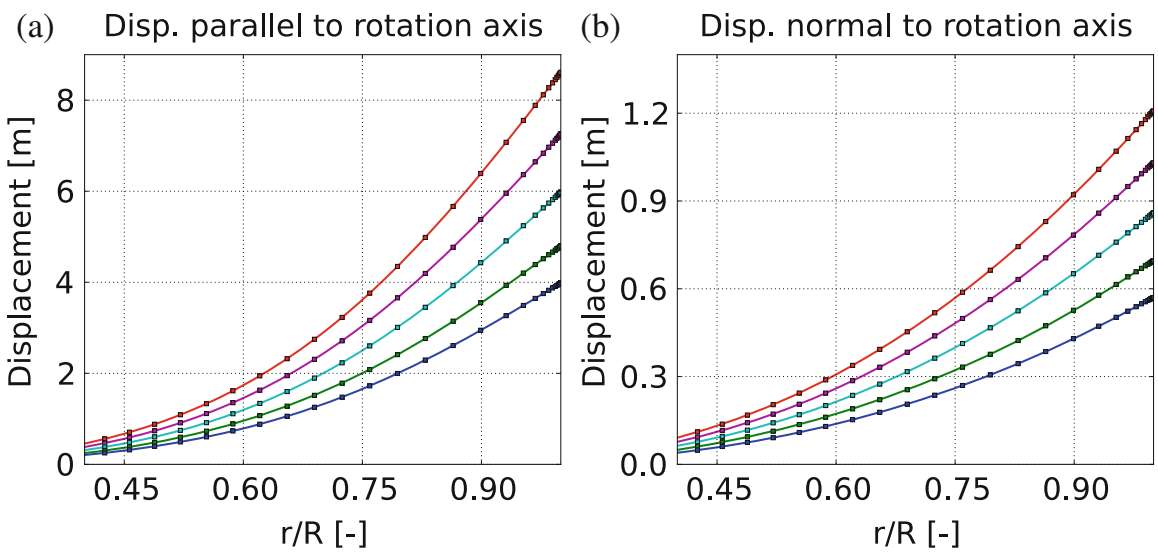

Fig. 18.17 DTU 10 MW RWT blade deformation in function of normalized radius for the prebent-precone configuration. (a) Blade axis displacement parallel to rotor axis. (b) Blade axis displacement normal to rotor axis

section, only the first six frequencies of the computed modal basis were used to model blade flexibility in the simulations.

Figure 18.17 shows the blade deformations for the flexible simulations of the prebent-precone rotor. Computed deformations were slightly higher than the ones corresponding to the straight rotor and previously displayed in Fig. 18.12. However, higher deformed blade tip/tower distances were observed for the prebent-precone configuration, due to its more conservative initial tower clearance. In order to illustrate this fact, Fig. 18.18 shows the reference (i.e. undeformed) and deformed blade axis coordinates for each of the presented aeroelastic computations. A global view is provided as well as a close zoom in order to properly contextualize the magnitude of the deformations. For the prebent-precone configuration, a blade tip/blade root alignment was observed for for the $10 \mathrm{~m} \mathrm{~s}^{-1}$ simulation. This operating point is indeed very close to the rated speed of the machine, verifying the prebending law defined at the design stage.

Computed global mechanical power coefficients of straight and prebent-precone configurations are shown in Fig. 18.19, together with a diagram superposing reference and deformed rotor geometries at rated speed. When considering the blades as rigid, a decrease in power was observed when introducing blade prebending and preconing. For the straight rotor, accounting for blade flexibility led to a reduction of the total power. This trend was reversed for the prebent-precone configuration, since the effect of flexibility tended to deform the blade towards a more orthogonal geometry with respect to the incoming flow (Fig. 18.19b). At rated speed, the power produced by the flexible prebent-precone blade was very close to the one computed for the rigid straight blade. An analogous plot regarding rotor global 


$\square$ FT_WSP11 $\square$ FT_WSP10 $\square \square$ FT_WSP09 $\square$ FT_WSP08 $\square$ FT_WSP07
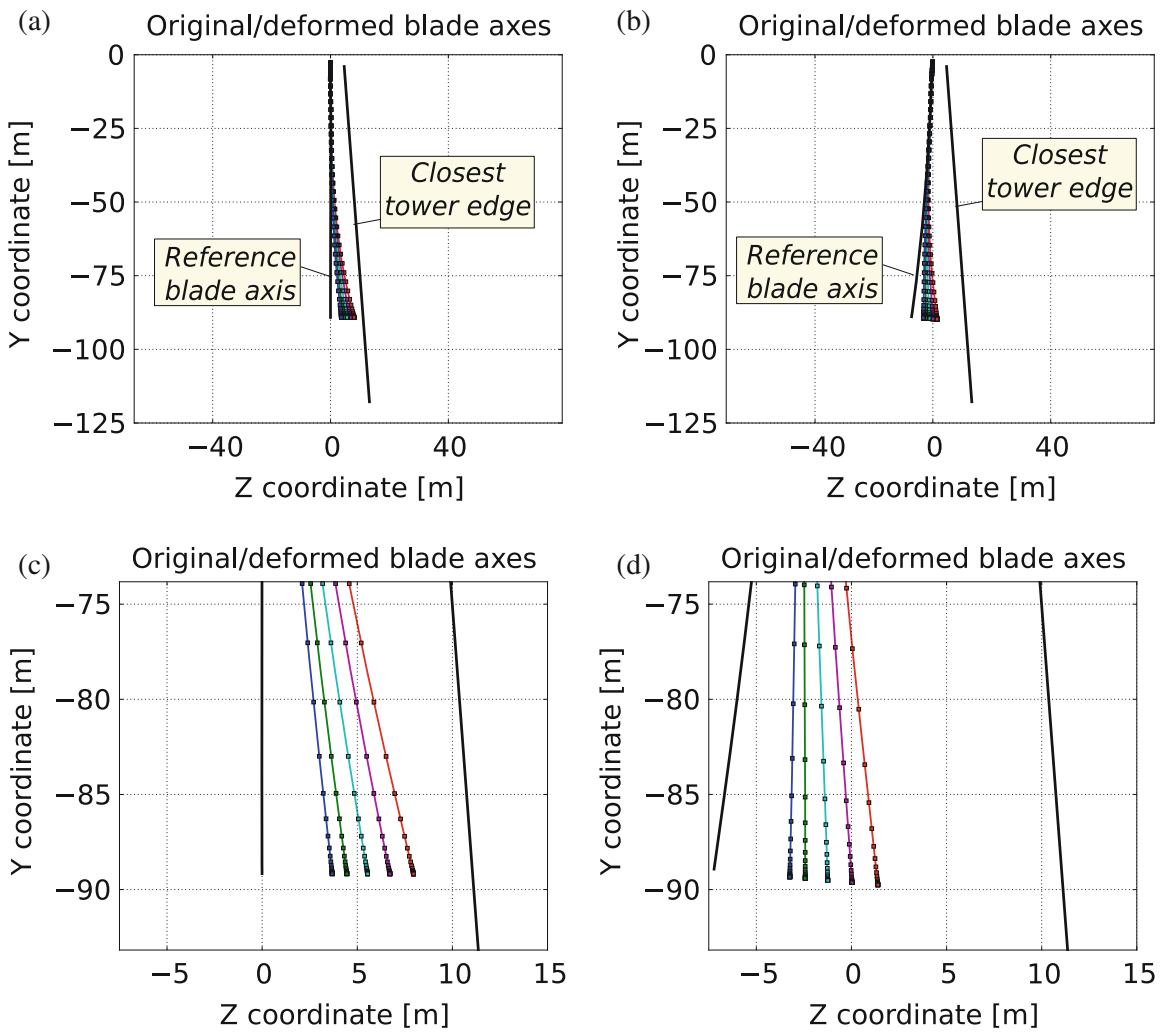

Fig. 18.18 Reference and deformed DTU 10 MW RWT blade axis coordinates with respect to closest tower edge. (a) Straight rotor (global view). (b) Prebent-precone rotor (global view). (c) Straight rotor (zoom). (d) Prebent-precone rotor (zoom)

thrust coefficient is included in Fig. 18.20. Lower thrust values were computed for the prebent-precone configuration with respect to the straight rotor. No significant differences between flexible and rigid simulations were observed for the prebentprecone configuration.

As a global conclusion, presented results show that aeroelastic analysis of DTU $10 \mathrm{MW}$ RWT cannot be performed without considering the prebending and the preconing of the blades. Indeed, even if it does not largely affect the natural frequencies of the blade, its shape modification influences the performances of the wind turbine. 

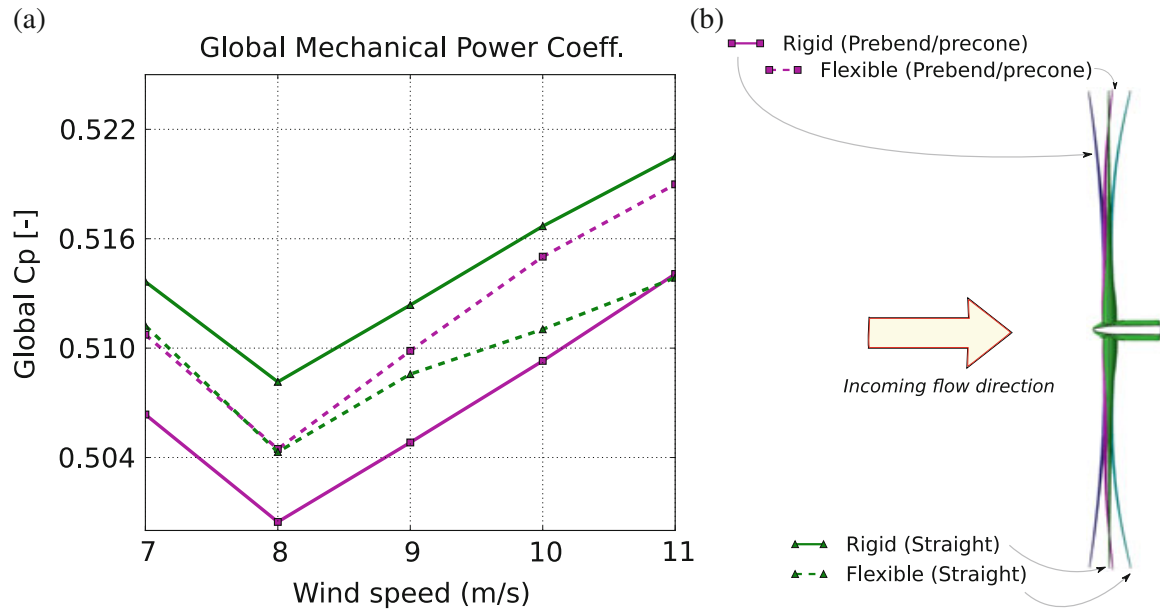

Fig. 18.19 Mechanical power coefficient of the DTU 10 MW RWT rotor, effects of prebendingpreconing and flexibility. (a) Global mechanical power coefficient. (b) View of deformed blades at rated speed

(a)

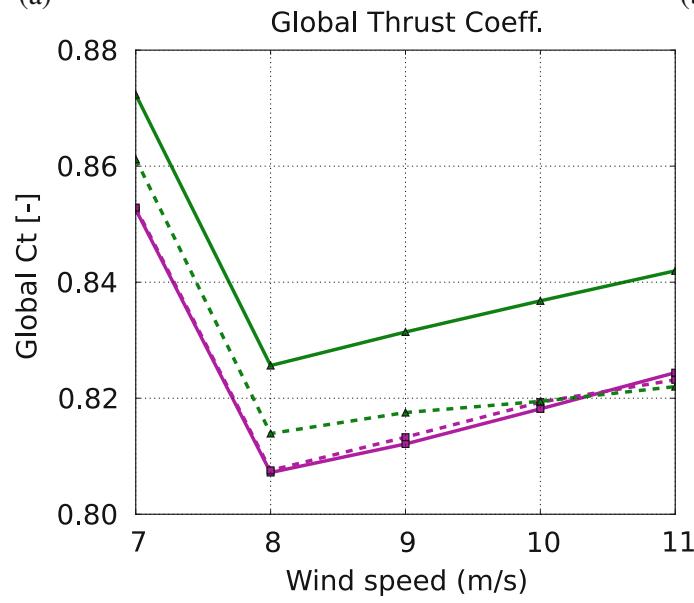

(b)

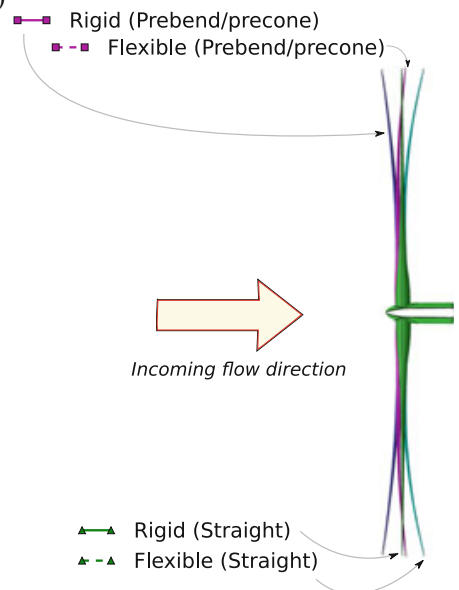

Fig. 18.20 Global thrust coefficient of the DTU 10 MW RWT rotor, effects of prebendingpreconing and flexibility. (a) Global thrust coefficient. (b) View of deformed blades at rated speed

\subsection{DTU 10 MW RWT Rotor-Tower Interactions Analysis}

In this section, flow complexity was increased by considering the DTU $10 \mathrm{MW}$ RWT tower in the computational domain. This more realistic scenario introduced an important unsteadiness in the flow due to the so-called rotor-tower 

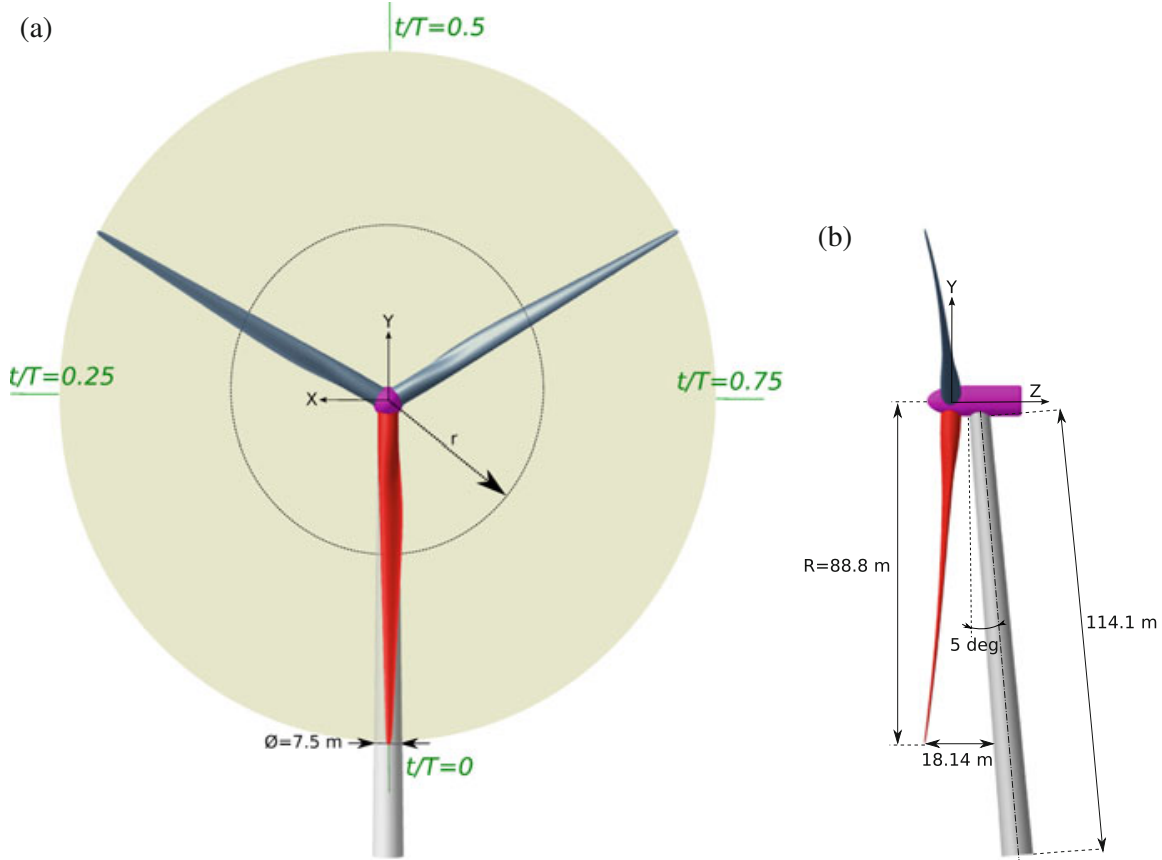

Fig. 18.21 Sketch of the DTU 10 MW RWT assembly. (a) Front view. (b) Side view

interactions. Hence, the use of more sophisticated numerical methods was required. In particular, the Non-linear Harmonic (NLH) approach presented by Vilmin et al. (2006) was used. In the NLH method, unsteady flow perturbations are Fourier decomposed. Navier-Stokes equations are then cast in the frequency domain, leading to the extraction of a set of transport equations for each harmonic. A single blade passage mesh is required. As a first approach and in order to keep the rotational periodicity of the problem, the incoming wind was assumed to be aligned with rotor axis. The hypothesis of rigid rotor blades was also made. The studied operating point was characterized by the following parameters:

- Incoming wind speed: $10.5 \mathrm{~m} \mathrm{~s}^{-1}$

- Rotor speed: $8.836 \mathrm{RPM}$

- Blade pitch: $0^{\circ}$

Figure 18.21 illustrates the main geometrical properties of the studied DTU 10 MW RWT assembly, based on its definition from Bak et al. (2013). The rotor axis was colinear with $\mathrm{Z}$ axis. A tilt angle of $5^{\circ}$ was considered between rotor and tower axes. Blades accounted for a precone angle of $2.5^{\circ}$ as well as a distributed prebending. Based on the disadvantageous effects on rotor performance found in Sect. 18.2.2, Gurney flaps were removed from blade geometry. In order to present the unsteady results of this section, the normalized time $t / T$ was used. In this context, $t$ is defined 
(a)

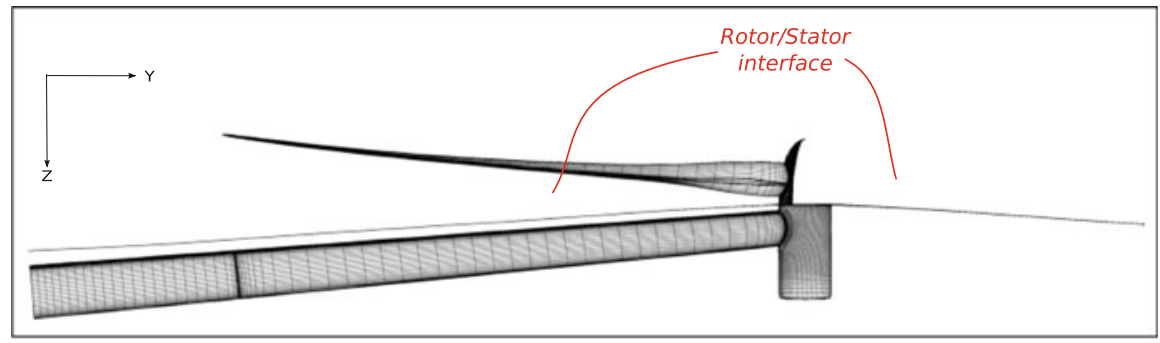

(b)

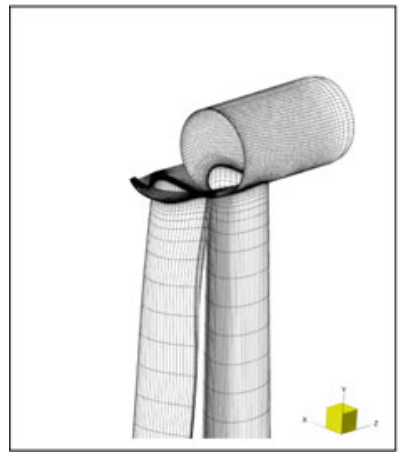

(c)

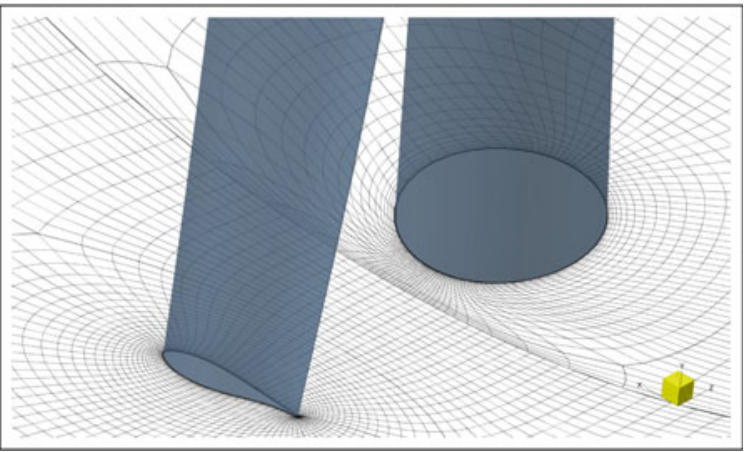

Fig. 18.22 DTU 10 MW RWT assembly mesh, 1 out of 2 mesh lines are skipped. (a) Surface mesh, global view. (b) Surface mesh, rotor detail. (c) Half-span cross-section grid line

as the already lapsed time in the current revolution and $T$ refers to the period of rotation. The DTU $10 \mathrm{MW}$ RWT operates in clockwise rotation, and it was assumed that at $t / T=0$ one of the blades was aligned with the tower axis. This particular blade, displayed in red in Fig. 18.21, is referred in this document as the observed blade.

To generate a suitable mesh for NLH computations, DTU 10 MW RWT blade sections defined in Bak et al. (2013) were imported in Autogrid5 ${ }^{\mathrm{TM}}$ structured grids generator (NUMECA International 2013a). Original nacelle, hub and tower geometries were also considered in the mesh generation process. To properly describe the boundary layer for the considered operating point, a first cell size of $3.0 \times 10^{-5} \mathrm{~m}$ was imposed around the blade. A rotor/stator interface crossing the DTU 10 MW RWT nacelle was defined in order to connect rotating and non-rotating computational domains. A single blade passage was meshed in the rotor side, while a $360^{\circ}$ grid was generated for the tower (or stator) region. Flow inlet and outlet were located at 2.2 and 3.2 blade radius from the nacelle, respectively. Figure 18.22 shows the complete generated mesh, accounting for 13 millions of nodes. For clarity purposes, 1 out of 2 mesh lines were skipped.

A total of nine harmonics were considered. The Spalart-Allmaras turbulence model (Spalart and Allmaras 1992) was used. A full non-matching non-reflecting 
Fig. 18.23 Iso-surface of 0.5 Q-criterion at $\frac{t}{T}=0.50$

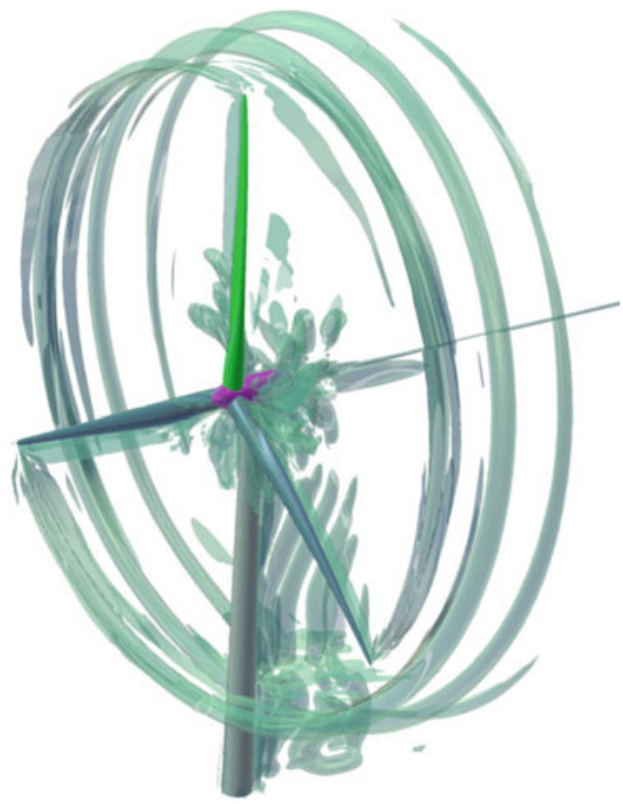

approach was employed for the modeling of the rotor/stator interface (Vilmin et al. 2006). First resolved rotor harmonic was located at $0.15 \mathrm{~Hz}$, corresponding to the rotational speed at the considered operating point. Since the DTU $10 \mathrm{MW}$ RWT has a three-bladed rotor, a frequency of $0.45 \mathrm{~Hz}$ was observed for the first tower harmonic. Even if flow variables are solved in the frequency domain, NLH results can be easily reconstructed in time in order to perform a more comprehensive postprocessing. This process is referred in this document as the time solution reconstruction.

The complexity of this unsteady problem could be already pointed out with the visualization of the flow at a given time. Figure 18.23 illustrates the iso-surfaces of Q-criterion for a value of 0.5 of the time reconstructed solution at $\frac{t}{T}=0.50$. Important vortical structures could be observed downstream of the tower. These were present all along the tower height. High vorticity regions were identified at low blade span range (where the DTU $10 \mathrm{MW}$ RWT is equipped with thicker airfoils). The generation of blade tip vortex was clearly visible. The collision of this structure with the tower led to an important increase of downstream vorticity.

The observed vorticity at low blade span can be related to the shedding phenomenon. Figure 18.24 shows the streamlines around the observed blade for a $r=20 m$ cross-section. Indeed, the low span suction side recirculation already identified for the rotor-only RANS computations was shed from the blade. This effect was especially visible when the blade approached the tower (i.e. for $\frac{t}{T}=0.00$ and $\frac{t}{T}=0.76$ ). A similar vortex shedding phenomenon was identified downstream of the tower all along its height. 
(a)

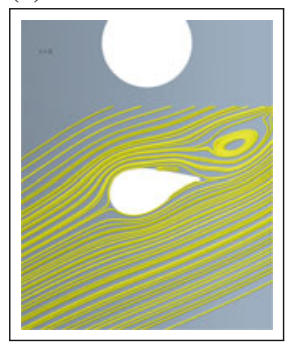

(b)

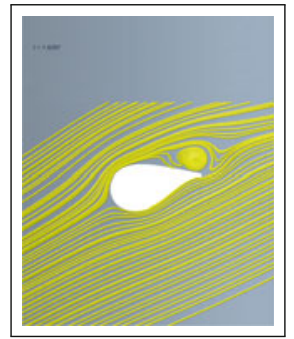

(c)

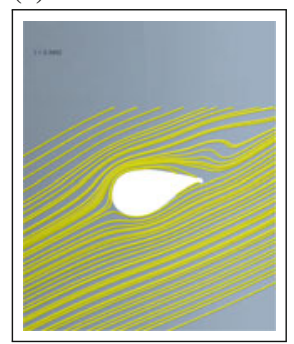

(d)

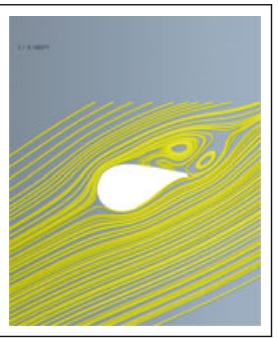

Fig. 18.24 Relative velocity streamlines around the observed blade for a $r=20 \mathrm{~m}$ cross-section. (a) $\frac{t}{T}=0.00$. (b) $\frac{t}{T}=0.24$. (c) $\frac{t}{T}=0.50$. (d) $\frac{t}{T}=0.76$

(a)

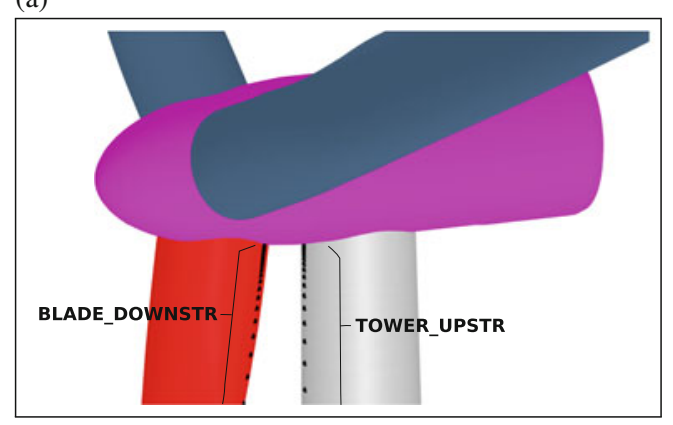

(b)

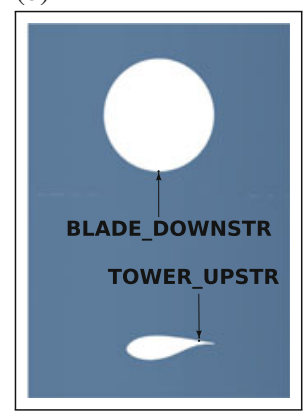

Fig. 18.25 Location of BLADE_DOWNSTR and TOWER_UPSTR sets of sensors. (a) DTU 10 MW RWT front view. (b) Cut at $r=44.5 \mathrm{~m}$

When characterizing the frequency content of the blade shedding, an important spanwise dependency was observed. Two sets of sensors were defined in order to have an overview of this relation: BLADE_DOWNSTR and TOWER_UPSTR, both installed all along a mesh line. While BLADE_DOWNSTR was positioned at the observed blade shedding location, TOWER_UPSTR intended to analyze the impact of the rotor perturbation on the tower (see Fig. 18.25).

Figure 18.26 illustrates the harmonic pressure amplitudes for every point included in BLADE_DOWNSTR and TOWER_UPSTR. The results are expressed as a function of the considered harmonic (referenced here as Harmonic order), and of the radial position of each point. The blade shedding phenomenon could be identified for BLADE_DOWNSTR at the vicinity of $20 \mathrm{~m}$. In this region, important harmonic amplitudes corresponding to the fifth harmonic were observed. The influence of blade shedding on the tower was visible in TOWER_UPSTR, where a shifting of the harmonic content towards higher frequencies was observed at low span.

Figure 18.27 shows rotor loads time evolution, where the effects of the bladetower alignment event are clearly visible at $\frac{t}{T}=0, \frac{1}{3}, \frac{2}{3}$. The corresponding result 

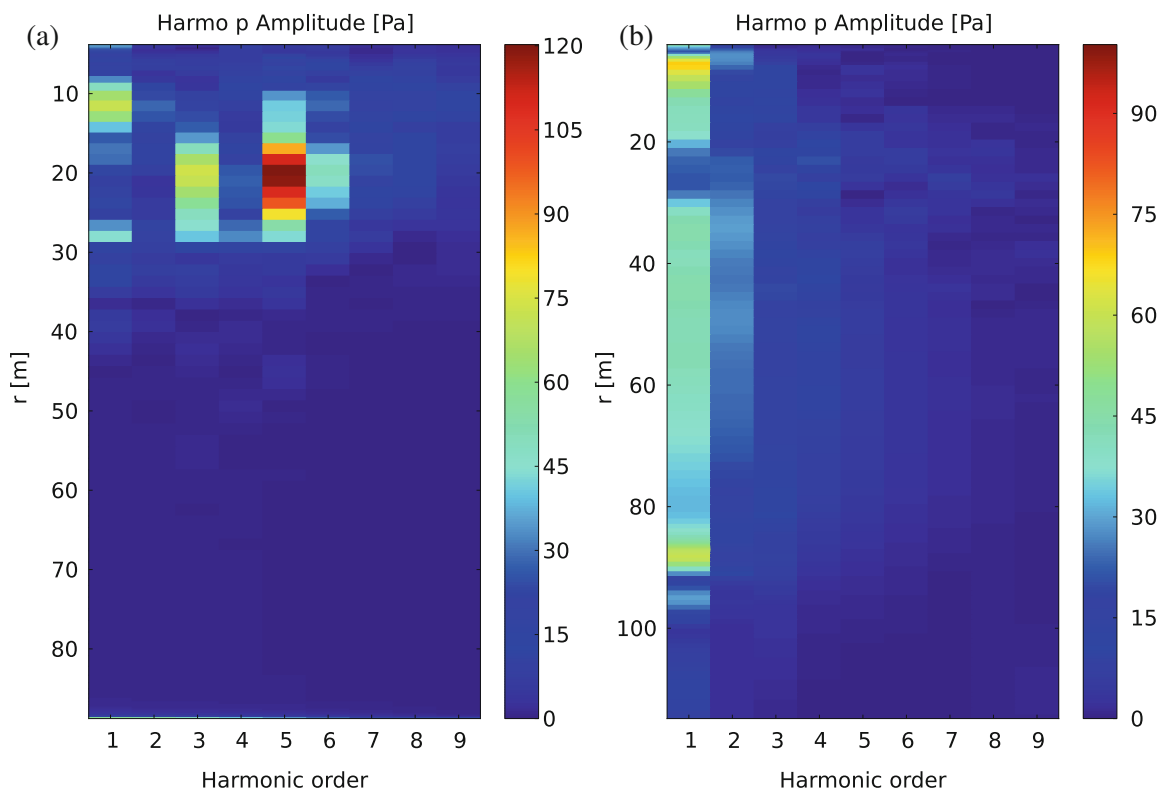

Fig. 18.26 Harmonic pressure amplitude $[\mathrm{Pa}]$ for the defined sets of sensors, as a function of $r$ [m]. (a) BLADE_DOWNSTR. (b) TOWER_UPSTR
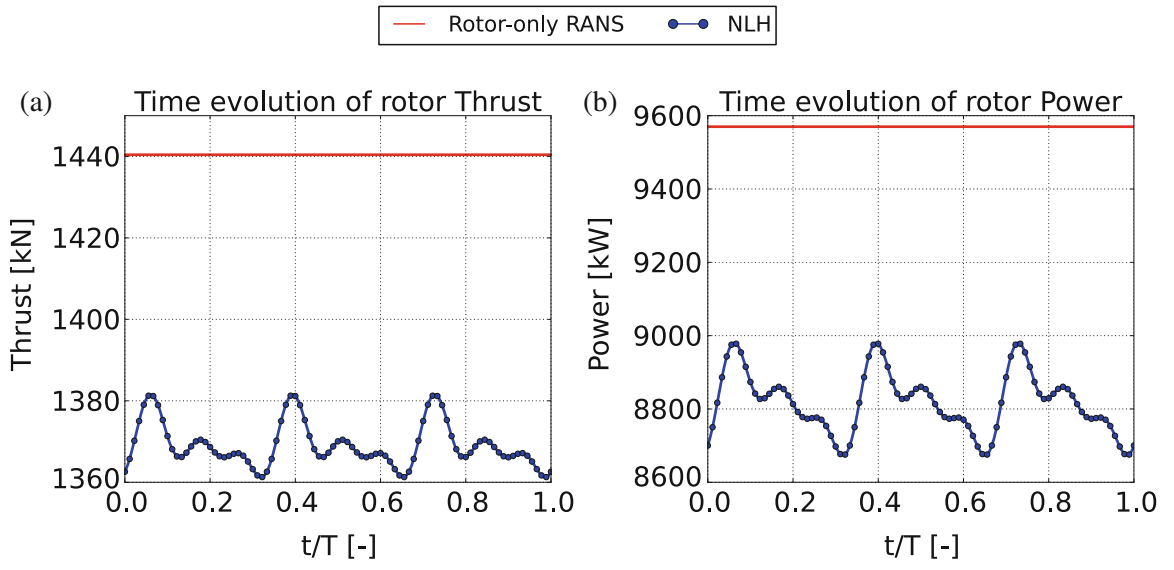

Fig. 18.27 DTU 10 MW RWT rotor loads as a function of normalized time. (a) Thrust [kN]. (b) Power $[\mathrm{kW}]$

for a rotor-only RANS simulation based on the set-up of Sect.18.2 is included for reference. Relative loads fluctuation amplitudes of $1 \%$ for the rotor thrust and $2 \%$ for the mechanical power were computed. The presence of the tower led to a time-averaged decrease of $5 \%$ of rotor thrust and $8 \%$ of mechanical power with 
respect to the corresponding rotor-only simulation. Therefore it can be concluded that the influence of the tower is not negligible when assessing the wind turbine performance.

\subsection{Conclusions and Future Work}

A numerical analysis of the DTU $10 \mathrm{MW}$ RWT reference wind turbine aerodynamics was presented and discussed. A three-dimensional CFD-based methodology was developed in order to tackle two challenging problems. On one hand, the impact of large OWT blade deflections on rotor performance (the so-called aeroelastic effects). On the other hand, the modeling of flow unsteadiness coming from the consideration of the tower in the CFD set-up (also referred as rotor-tower interactions).

The issue of aeroelasticity was studied in a rotor-only framework. First simulations aimed to verify the obtained results for a straight and rigid configuration regarding to CFD simulations performed by other authors. For both methodologies, computed flow separation and rotor loads were in good agreement. After this initial comparison the developed tool was extended by including a structural model of the blade, represented by its natural frequencies and deformed shapes. This enhanced numerical approach was used in order to study the influence of two different geometrical modifications of the blade on final rotor performance and aeroelastic response. First, the impact of Gurney flaps installation was discussed. No re-attachment of the suction surface separation bubble was observed after the introduction of these devices, and a wider pressure surface recirculation zone was identified. The evaluation of the total mechanical power and thrust showed that Gurney flaps reduced the global performance of the DTU $10 \mathrm{MW}$ RWT rotor for the considered operating points. This remark could be made for both rigid and flexible configurations. For the latter case blade tip deformations of $8 \mathrm{~m}$ were computed at rated speed, leading to a power production decrease of $1.4 \%$. It can be concluded that the consideration of blade flexibility is necessary in order to properly estimate the final rotor performance. Secondly, the results of a prebent-precone rotor were compared with the standard straight configuration. When considering the blades as rigid, the combination of both geometrical modifications led to a decrease of the computed rotor loads. At rated speed, reductions of $1 \%$ of thrust and $2 \%$ of mechanical power were observed. When analyzing the corresponding flexible blade configurations, the effect of aeroelasticity on rotor performance was reversed. Indeed, while a reduction in the generated power was observed for the deformed straight rotor, an increase was found for the prebent-precone configuration. This inversion was explained by the deformed rotor geometries, since for the prebentprecone simulations the blade flexibility tended to recover the orthogonality with respect to the incoming flow. These results show that aeroelastic analysis of DTU $10 \mathrm{MW}$ RWT cannot be performed without considering the prebending and the preconing of the blades. 
Finally, the NLH method was applied in order to study the whole DTU $10 \mathrm{MW}$ RWT assembly (including the tower). This approach was able to capture the complex unsteady aerodynamics related to rotor-tower interactions. The presence of the tower had a direct impact on rotor performance, justifying the numerical analysis of the full machine. Decreases of around $5 \%$ of time-averaged rotor thrust and $8 \%$ of power were computed. These reductions are in line with previous studies based on other wind turbines (Hsu and Bazilevs 2012; Hsu et al. 2014; Carrión 2014; Li 2014). Local unsteady flow patterns around the whole DTU 10 MW RWT assembly were also characterized. In particular, both tower and blade shedding phenomena were identified. The latter effect was found to be related to high frequencies. In particular, the considered operating point revealed a blade shedding frequency corresponding to the fifth harmonic. This harmonic order is coherent with the results of previous CFD computations of the NREL Phase VI (Le Pape and Lecanu 2004; Li 2014). Regarding the blade-tower alignment event, loads fluctuation relative amplitudes of $1 \%$ for the rotor thrust and $2 \%$ for the mechanical power were computed.

Future work will be devoted to extend the capabilities of the NLH method to account for a structural model of the blades, in order to assess the combined impact of rotor flexibility and flow unsteadiness on rotor performance. Additionally, the studied DTU $10 \mathrm{MW}$ RWT operating range will be extended to higher wind speeds to evaluate the performance of the presented methodology when considering more important angles of attack.

Acknowledgements The authors acknowledge the European Commission for their research grant under the project FP7-PEOPLE-2012-ITN 309395 MARE - WINT (new MAterials and REliability in offshore WINd Turbines technology), as well as all the members from FINETM/Turbo team of NUMECA International for their valuable and active contribution.

Open Access This chapter is distributed under the terms of the Creative Commons AttributionNonCommercial 4.0 International License (http://creativecommons.org/licenses/by-nc/4.0/), which permits any noncommercial use, duplication, adaptation, distribution and reproduction in any medium or format, as long as you give appropriate credit to the original author(s) and the source, provide a link to the Creative Commons license and indicate if changes were made.

The images or other third party material in this chapter are included in the work's Creative Commons license, unless indicated otherwise in the credit line; if such material is not included in the work's Creative Commons license and the respective action is not permitted by statutory regulation, users will need to obtain permission from the license holder to duplicate, adapt or reproduce the material.

\section{References}

Bak C, Zahle F, Bitsche R, et al (2013) The DTU 10-MW reference wind turbine. In: DTU orbit - the research information system. Available via Technical University of Denmark. http://orbit.dtu.dk/files/55645274/The_DTU_10MW_Reference_Turbine_ Christian_Bak.pdf. Accessed 08 Apr 2016 
Carrión M (2014) Low Mach number CFD for wind turbine analysis. Dissertation, University of Liverpool

Corson D, Griffith DT, Ashwill T, et al (2012) Investigating aeroelastic performance of multi-mega watt wind turbine rotors using CFD. Paper presented at the 53rd AIAA/ASME/ASCE/AHS/ASC structures, structural dynamics and materials co-located conferences, Honululu, 23-26 April 2012

Debrabandere F (2014) Computational methods for industrial fluid-structure interactions. Dissertation, Université de Mons (UMONS)

Elfarra MA, Sezer-Uzol N, Akmandor IS (2014) NREL VI rotor blade: numerical investigation and winglet design and optimization using CFD. Wind Energy 17(4):605-626

Fan Z, Kang S (2009) Numerical simulations of the aerodynamics performance of Horizontal Axis Wind Turbines. In: Tao Y, Ma C (eds) UECTC 2009. Inaugural US-EU-China thermophysics conference-renewable energy, Beijing, May 2009. American Society of Mechanical Engineers (ASME), Houston. doi:10.1115/1.802908.paper16

Gaunaa M, Zahle F, Sørensen NN, et al (2013) Rotor performance enhancement using slats on the Inner part of a $10 \mathrm{MW}$ rotor. Paper presented at the European wind energy conference and exhibition (EWEA), Vienna, 4-7 February 2013

Heege A, Gaull A, Horcas SG, et al (2013) Experiences in controller adaptations of floating wind turbines through advanced numerical simulation. Paper presented at the AWEA WINDPOWER 2013 conference and exhibition, Chicago, 5-8 May 2013

Horcas SG, Debrabandere F, Tartinville B, et al (2014) Mesh deformation tool for Offshore Wind Turbines fluid-structure interaction. In: Abstracts of the 11th World Congress on Computational Mechanics (WCCM XI), Barcelona, 20-25 July 2014

Horcas SG, Debrabandere F, Tartinville B, et al (2015a) A new, high fidelity offshore wind turbines aeroelasticity prediction method with significant CPU time reduction. Poster presented at the Offshore 2015. European Wind Energy Association, Copenhagen, 10-12 March 2015

Horcas SG, Debrabandere F, Tartinville B, et al (2015b) Hybrid mesh deformation tool for offshorewind turbines aeroelasticity prediction. In: Ferrer E, Montlaur A (eds) CFD for wind and tidal offshore turbines SE - 8, Springer tracts in mechanical engineering. Springer, Heidelberg, pp 83-94

Hsu MC, Bazilevs Y (2012) Fluid-structure interaction modeling of wind turbines: simulating the full machine. Comput Mech 50(6):821-833

Hsu MC, Akkerman I, Bazilevs Y (2014) Finite element simulation of wind turbine aerodynamics: validation study using NREL Phase VI experiment. Wind Energy 17:461-481

Jonkman JM, Buhl ML (2007) Development and verification of a fully coupled simulator for offshore wind turbines, NREL/CP-500-40979. In: National Renewable Energy Laboratory documents. Available via NREL. http://www.nrel.gov/docs/fy07osti/40979.pdf. Accessed 11 Apr 2016

Larsen T, Hansen A (2007) How to HAWC2, the User's manual. In: DTU orbit - the research information system. Available via Technical University of Denmark. http://orbit.dtu.dk/files/ 7703110/ris_r_1597.pdf. Accessed 11 Apr 2016

Le Pape A, Lecanu J (2004) 3D Navier-Stokes computations of a stall-regulated wind turbine. Wind Energy 7(4):309-324

Li Y (2014) Coupled computational fluid dynamics/multibody dynamics method with application to wind turbine simulations. Dissertation, University of Iowa

Liebeck RH (1978) Design of subsonic airfoils for high lift. J. Aircraft 15(9):547-561

Lynch CE (2011) Advanced CFD methods for wind turbine analysis. Dissertation, Georgia Institue of Technology

NUMECA International (2013a) Autogrid5 ${ }^{\mathrm{TM}}$ v9.0 User Manual, NUMECA, Brussels

NUMECA International (2013b) FINE ${ }^{\mathrm{TM}} /$ Turbo v9.0 User Manual, NUMECA, Brussels

Simulia DSC (2008) Abaqus Analysis version 6.8 User's Manual, Simulia, Waltham

Sørensen NN (1995) General purpose flow solver applied to flow over hills. Ris $\varnothing$ National Laboratory, Roskilde 
Spalart P, Allmaras S (1992) A one-equation turbulence model for aerodynamic flows. In: Abstracts of the 30th AIAA aerospace sciences meeting and exhibit, AIAA, Reno, 6-9 January 1992

Suárez JM, Doerffer P, Szulc O (2015a) CFD validated technique for prediction of aerodynamic characteristics on horizontal axis wind energy turbines. Poster presented at the Offshore 2015. European Wind Energy Association, Copenhagen, 10-12 March 2015

Suárez JM, Doerffer P, Szulc O, et al (2015b) Aerodynamic analysis of wind turbine rotor blades. Task Quart 19(2):129-140

Troldborg N, Zahle F, Sørensen NN (2015) Simulation of a MW rotor equipped with vortex generators using CFD and an actuator shape model. In: 53rd AIAA Aerospace Sciences Meeting, American Institute of Aeronautics and Astronautics, Kissimmee, 5-9 July 2015

Vilmin S, Lorrain E, Hirsch C, et al (2006) Unsteady flow modeling across the rotor/stator interface using the nonlinear harmonic method. In: Abstracts of the ASME Turbo Expo 2006: power for land, sea and air, American Society of Mechanical Engineers, Barcelona, 8-11 May 2006

Wang Q, Zhou H, Wan D (2012) Numerical simulation of wind turbine blade-tower interaction. J Mar Sci Appl 11(3):321-327

Yu DO, Kwon OJ (2014) Predicting wind turbine blade loads and aeroelastic response using a coupled CFD-CSD method. Renewable Energy 70:184-196

Zahle F, Sørensen NN (2008) Overset grid flow simulation on a modern wind turbine. In: Abstracts of the 26th AIAA applied aerodynamics conference, guidance, navigation, and control and co-located conferences, American Institute of Aeronautics and Astronautics, Honolulu, 18-21 August 2008

Zahle F, Sørensen NN (2011) Characterization of the unsteady flow in the nacelle region of a modern wind turbine. Wind Energy 14(2):271-283

Zahle F, Sørensen NN, Johansen J (2009) Wind turbine rotor-tower interaction using an incompressible overset grid method. Wind Energy 12(6):594-619

Zahle F, Bak C, Guntur S, et al (2014) Comprehensive aerodynamic analysis of a $10 \mathrm{MW}$ wind turbine rotor using 3D CFD. In: Abstracts of the 32nd wind energy symposium, American Institute of Aeronautics and Astronautics, National Harbor, 13-17 January 2014 